\title{
Knowledge, attitude and practice of nursing ethics and law among nurses at Federal Medical Centre, Bida
}

\author{
Danjuma Aliyu ${ }^{1, ~ *, ~ I b r a h i m ~ T a i w o ~ A d e l e k e ~}{ }^{2,3,4}$, Sunday Oluwafemi Omoniyi ${ }^{5}$, \\ Balarabe Ayuba Samaila ${ }^{1}$, AliyuAdamu', Aisha Yahaya Abubakar ${ }^{7}$ \\ ${ }^{1}$ Department of Nursing Services, Ahmadu Bello University Teaching Hospital, Zaria,Nigeria \\ ${ }^{2}$ Department of Health Information, Federal Medical Centre, Bida,Nigeria \\ ${ }^{3}$ Centre for Health \& Allied Researches, Bida, Nigeria \\ ${ }^{4}$ Health Informatics Research Initiatives in Nigeria, Bida, Nigeria \\ ${ }^{5}$ Department of Nursing Services, Federal Medical Centre, Bida, Nigeria \\ ${ }^{6}$ Niger State College of Nursing Sciences, Bida, Nigeria \\ ${ }^{7}$ School of Nursing and Midwifery, Gusau, Nigeria
}

\section{Email address:}

aliyudanjuma19@gmail.com (D. Aliyu), ibratadeleke_aliseyin@yahoo.com (I. T. Adeleke), omonisunday@yahoo.com (S. O. Omoniyi), balarabeayubas@gmail.com (B. A. Samaila), alimuye@yahoo.com (A. Adamu), aisha_yahaya@yahoo.com (A. Y. Abubakar)

\section{To cite this article:}

Danjuma Aliyu, Ibrahim Taiwo Adeleke, Sunday Oluwafemi Omoniyi, Balarabe Ayuba Samaila, Aliyu Adamu, Aisha Yahaya Abubakar. Knowledge, Attitude and Practice of Nursing Ethics and Law among Nurses at Federal Medical Centre, Bida. American Journal of Health Research. Special Issue: Health Information Technology in Developing Nations: Challenges and Prospects Health Information Technology. Vol. 3, No. 1-1, 2015, pp. 32-37. doi: 10.11648/j.ajhr.s.2015030101.15

\begin{abstract}
It is universally acknowledged that nursing profession is guided by both ethic and legal principles as it is the tools for professional discipline which gives the nurse a broad idea of what is expected of her as she moves from the protective ambiance of school into the society. Social changes such as right to healthcare, increasing cost of healthcare and conflicting institutional policies create ethico-legal problems for the nurses. This study is a cross-sectional descriptive study designed to determine knowledge, attitude and practice of nursing ethics and law among nurses at Federal Medical Centre, Bida. A total of 149 questionnaires were administered using simple random sampling technique. The main findings of this study established that the participating nurses possess considerably good knowledge, attitude and practice of nursing ethics and law. Majority $(82.6 \%)$ of the participants obtained knowledge about ethical dilemma mostly (36\%) through seminar/workshops followed by those $(31 \%)$ who knew about it right from their respective schools of training. Three factors of professional progression in this study; professional qualification $(p=.015)$, years of experience $(p=.000)$ and rank $(p=.002)$ had noticeable effects on knowledge, attitude and practice of nursing ethics and law among the participants. Several options were identified by the participants as remedies to reduce the incidence of ethical and legal issues in their practice area. These include; periodic workshops, adherence to nursing code of ethics, utilization of hospital policy and personal development. Although participants differedon whether providers should adhere to patients' wish at all times,they possess good knowledge on nursing ethics and law. The overall results of the study suggested that there is need for nurses to understand the relationship and limitations between ethics, hospital policy and legal issues as they relate to nursing practice.
\end{abstract}

Keywords: Beneficence, Confidentiality, Dilemma, Nursing Code of Ethics, Nurse's Ordinance, Nursing Practice Act, Ethico-Legal Issues in Nursing, Patient Safety

\section{Introduction}

Nursing is a caring profession which has itsrelevance and direct impact on the life, health and well-being of individuals, families and communities [1]. Nursing profession is guided by both ethics and legal principles as they are tools for professional discipline which gives the nurse a broad idea of what is expected of her as she moves from the protective climate of school into the society [2]. Ethics and the law are closely related in concepts, such as rights and justice, have both ethical and legal significance, they are both instruments of regulation and prescriptions onhow people ought to act in 
response to one another [3]. Nursing ethics and law are necessary in nursing because nursing is concerned with providing services that impact on human life and health and some of the situations the nurse encounters in practice pose dilemma that if not well handled,may impact negatively on the client and all who are concerned. Standards must therefore be set to guide the nurse to conduct herself properly, make adequate decisions and carry out actions that are appropriate and safe for the client and thus protect herselffrom litigation [1]. Nursing practice is regulated to ensure that standards and scope of nursing practice are maintained to achieve safe practices [1, 4]. The practice involves the use of clinical judgment in the provision of care to enable people to improve, maintain, or receive health, to cope with health problems, and to achieve the best possible quality of life [5].

Good nursing practice requires that practical efficacy and ethics are given equal consideration [3].The authority for the practice of nursing is based upon a contract that delineates professional rights and responsibilities as well as mechanism for public accountability. Nursing practice in virtually all nations is governed by law. Each country may have different act but, they all have common purpose to protect the public [6]. This is because every nursing specialty has legal consideration or implications for the practitioners [7-8]. Aside the interactive nature of nursing practice, documentation of nursing activities is very important as it is the legal tender for any nursing interaction and care. Nursing documentation is usually treated as a legal issue which the nurse must take very serious [9]. Adekilekun[10] states that proper documentation is another common source of litigation in Nigeria. A proper documentation of the date, time and history (in brief), positive physical findings, investigations, treatment and instructions to the junior staff and the patient are necessary.Advance in medicine and the emergence of new infectious diseases such as HIV/AIDS has created serious clinical and public health challenges and dilemmas, especially, with the issue of medical confidentiality. These challenges reinforce more than ever before, the need for moral judgment in decision making for the achievement of professional standards in nursing education and nursing practice. In any case, nurses are often confronted by ethical problems that require them to make ethical decisions that are in the best interest of the client and as well, preserve the integrity of all concerned [1].

Nurses participate in ethical decision-making on a daily basis and are frequently required to make moral choices.Opinions of nurses often reflect a moral evaluation of right or wrong and, at times, nurses are uncertain about the 'right' way to behave [3]. This is especially, with the increasing population in the sub-Sahara African nations like Nigeria, couple with the discernible low economic trends. In addition, the demand for healthcare services has far exceeded supply especially among the less privileged members of the society. All these challenges present nurses and other healthcare providers with ethical dilemmas in their professional practice and responsibilities [11]. Unfortunately, a study byAdeleke et al [12] has shown that healthcare providers do not understand their respective responsibility toward medical confidentiality.Amsale [4] asserted that lack of correct approach in addressing different contextual issue in nursing may lead the nurse to ethical dilemma. Research [5] has shown that $77.6 \%$ of nurses in Nigerian have knowledge deficit in legal aspects of nursing practice. Although it is evident that nursing law and ethics is important in healthcare practice, there are few scientific evidences to illustrate how versed are Nigerian nurses with regards to this subject. In line with this, there is an ongoing campaign for full implementation of the National Health Insurance Scheme (NHIS) in Nigeria. This scheme will further put dilemmas on nurses as it tends to provoke kinds of litigations by healthcare consumers as they become more aware of their healthcare needs and providers' obligations [5]. It is against this backdrop that this study aimed at determining knowledge, attitude and practice (KAP) of nursing ethics and law among nurses at Federal Medical CentreBida (FMCB), Nigeria.

\section{Methods}

\subsection{Background to the Study Area}

The study was carried out at Federal Medical Centre Bida. This 200-bed facility is the only tertiary healthcare outfit with diverse specialties.

\subsection{Study Design}

This is a cross-sectional descriptive study on KAP of Nursing Ethics and Law among nurses at Federal Medical Centre Bida (FMCB), Nigeria.

\subsection{Study Population}

The target population for this study includes all the 244 nurses employed by FMCB as at July 2014.

\subsection{Data Collection Tools}

A 21-item questionnaire about knowledge, attitude and practice of nursing ethics and law was administered to 149 selected samples. The questionnaire was administered on the $4^{\text {th }}$ of July 2014 during nurse's continuous professional education (CPE) session of nurses at FMCB.

\subsection{Sampling Techniques and Sample Size}

Participants in this study were selected using a simple random sampling technique with rumpled paper chips bearing "Yes" or "No". A ballot box containing rumple chips paper tagged (Yes, 149, No, 95) was presented to the attendees at the forum, giving every attendee equal opportunity to participate in the study. Those who picked "Yes" were automatically recruited for the study. A 10 percent attrition rate was used. The sample size was calculated using online sample size calculating software.The input criteria, for sample size estimation was set at confidence level of 95 percent, confidence interval of 5 and 
target population for the study 244. A total sample size of 149 nurses across the board was achieved. Sample size calculator available at:(www.surveysystem.com).Accessed on $31^{\text {st }}$ August, 2013.

\subsection{Data Analysis and Management}

Data analysis was done using SPSS 16.0 for windows. Descriptive analysis was computed on categorical data using Mean and Standard Deviation while test for statistical significance was determined using Chi-square $\left(\chi^{2}\right)$ and pvalue set at $p=.05$.

\subsection{Ethics}

Ethics approval was obtained from the Ethics and Research Review Committee of Federal Medical Centre Bida. Permission was sought from individual participants before administration of the questionnaire.

\section{Results}

\subsection{Participants' Socio-Demographic Characteristics}

Table 1 below shows that a total of one hundred and forty nurses participated in this study giving a response rate of $94 \%$. Of all the participants, the majority $(117,83.6 \%)$ were female with a female-male ratio of 5.1:1.More than three quarter $(105,76 \%)$ of the participants were married and more than half of them were between the ages of 30-44 with mean age of $38 \pm 9$ years.

Table 1. Socio-demographic data of the participants

\begin{tabular}{lll}
\hline & Frequency & Percentage \\
\hline Sex & 23 & \\
Male & 117 & 16.4 \\
Female & $\mathrm{n}=140$ & 83.6 \\
& & 100 \\
Marital status & 30 & \\
Single & 105 & 22 \\
Married & 3 & 76 \\
Widowed & $\mathrm{n}=138$ & 2 \\
& & 100 \\
Age group & 2 & \\
$20-24$ & 9 & 1.6 \\
$25-29$ & 25 & 7.3 \\
$30-34$ & 40 & 20.3 \\
$35-39$ & 25 & 33 \\
$40-44$ & 12 & 20.3 \\
$45-49$ & 7 & 9.8 \\
$50-54$ & 3 & 5.7 \\
$55-59$ & 0 & 2 \\
$60-65$ & $\mathrm{n}=123$ & 0 \\
& & 100 \\
\hline
\end{tabular}

\subsection{Professional Characteristics}

From Table 2, there were more specialized nurses 98 (77.2\%) among the participants and the majority $120(87.6 \%)$ were below 20 years in professional nursing service. The sizeable majority 124 (89) of the participants were between the rank of principal nursing officers and staff nurses. .
Table 2. Professional features of the participants

\begin{tabular}{lll}
\hline & Frequency & Percentage \\
\hline Professional qualification & & \\
RN* & 0 & 0 \\
RN with SRN* & 98 & 77.2 \\
RN,SRN with B.Sc. ${ }^{*}$ & 14 & 11 \\
RN,SRN with Master & 3 & 2.4 \\
RN,SRN with other certificate & 12 & 9.4 \\
& $\mathrm{n}=127$ & 100 \\
Years of experience & & \\
55yrs & 27 & 19.7 \\
6-10yrs & 37 & 27 \\
11-15yrs & 46 & 33.6 \\
16-20yrs & 10 & 7 \\
21-25yrs & 7 & 5 \\
26-30yrs & 7 & 5 \\
31-35yrs & 1 & 0.7 \\
$\geq 36 y r s$ & 3 & 2 \\
& $\mathrm{n}=137$ & 100 \\
Professional ranks & & \\
Chief nursing officer & 5 & 3.6 \\
Assistant chief nursing officer & 10 & 7.2 \\
Principal nursing officer & 24 & 17.3 \\
Senior nursing officer & 34 & 24 \\
Nursing officer & 37 & 27 \\
Staff nurse & 29 & 20.9 \\
& $\mathrm{n}=139$ & 100 \\
\hline
\end{tabular}

$* \mathrm{RN}=$ Registered nurse; $* \mathrm{SRN}=$ Specialized registered nurse; *B.Sc. $=$ Bachelor of science

\subsection{Knowledge on Nursing Ethics and Law}

Table 3 demonstrates participants' knowledge on nursing ethics and law. Majority of the participants $114(82.6 \%)$ Possess good knowledge of ethical dilemma and all (100 percent) of the participants indicated that documentation of nursing activities can be tendered in the law suits as evidence.

Table 3. Participant's knowledge on Nursing Ethics and Law

\begin{tabular}{lcccc}
\hline & $\mathbf{N}$ & Yes $(\%)$ & No (\%) & $\begin{array}{l}\text { Unsure } \\
(\%)\end{array}$ \\
\hline Statement & & & & \\
\hline $\begin{array}{l}\text { Have you heard of ethical } \\
\text { dilemma before }\end{array}$ & 138 & $114(82.6)$ & $15(10.9)$ & $9(6.5)$ \\
$\begin{array}{l}\text { Ethical dilemmas require an } \\
\text { individual to make a choice } \\
\text { between two equal }\end{array}$ & 129 & $123(95.3)$ & $6(4.7)$ & $0(0)$ \\
$\begin{array}{l}\text { unfavourable alternatives } \\
\text { Code of nursing ethics sets } \\
\text { out the ethical behaviours } \\
\text { expected of all registered } \\
\text { nurses }\end{array}$ & 139 & $137(98.6)$ & $2(1.4)$ & $0(0)$ \\
$\begin{array}{l}\text { Documentation of nursing } \\
\text { activities can be tendered in } \\
\text { the law suits as evidence }\end{array}$ & 139 & $139(100)$ & $0(0)$ & $0(0)$ \\
$\begin{array}{l}\text { Does Nigeria constitution } \\
\text { legalized termination of } \\
\text { pregnancy }\end{array}$ & 134 & $7(5)$ & $112(84)$ & $15(11)$ \\
\hline
\end{tabular}

\subsection{Knowledge on Beneficence and Non-Maleficence}

Beneficence and non-maleficence are two ethical principles that are based on doing or promoting good and avoid doing harm in any situation. It is significant to note that $77(65 \%)$ of the participants in this study knew the correct 
option that defined non-maleficence.On the other hand, majority $68(54 \%)$ of the participants were not acquainted with the best option that defined beneficence.

\subsection{Source of Information about Ethical Dilemma}

Information'sare facts provided or learned about something or someone. It is remarkable to note that $51(36 \%)$ of the participants indicated that their main source of information about ethical dilemma was through seminar/workshops, 43 (31\%)at school and 34 (24\%) through personal readings of books. In a related development, twothird $(66 \%)$ of the participants indicated that they will approach their unit in-charge when faced with ethical and legal problems while (17.1\%) specified the head of their department.

\subsection{Participants' Attitude towards Nursing Ethics and Law}

More than half of the participants $72(51 \%)$ believed that patients wish must always be adhered to. On the contrary, a greater portion $104(74 \%)$ opposed the thought to oblige patient'swishesto die. Likewise, the majority 116 (83\%) of the participants admitted that consent should be obtained for both operations and nursing procedures.

\subsection{Approach to Ethical Dilemma}

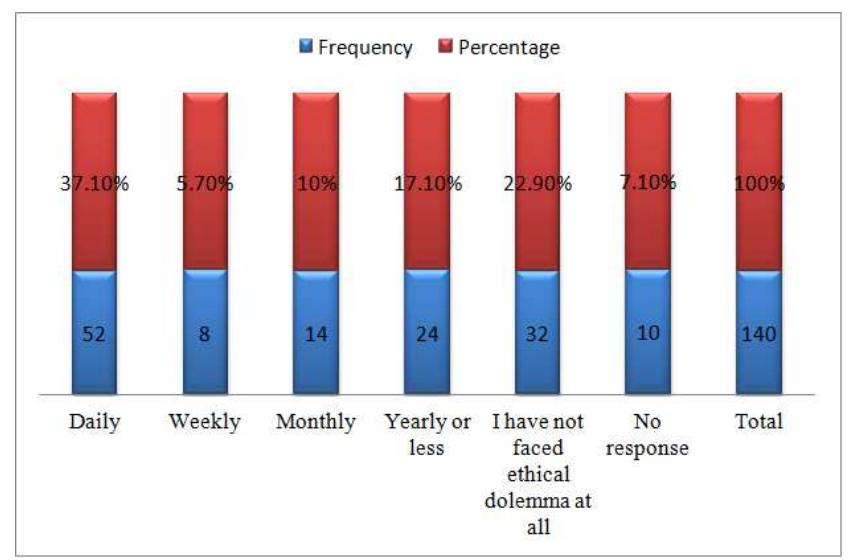

Figure 1. Practice of Nursing Ethics and law

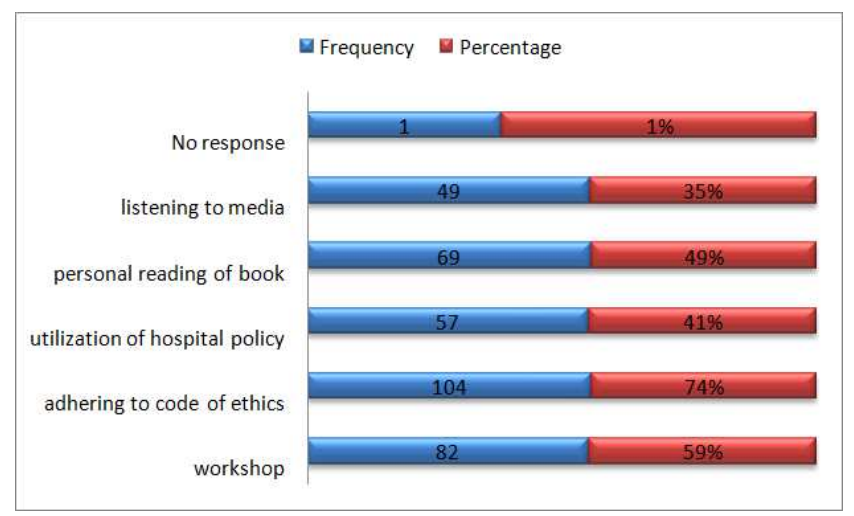

Figure 2. Mechanisms for the reduction of ethical and legal issues

Fig1 explains that $52(37.1 \%)$ of the participants encountered ethical problems at their workplace while 32
$(22.9 \%)$ had never encountered such problemthroughout their life time.

Figure 2 presents participants' opinions on approaches in reducing ethical and legal issues. Notably, 104 (74\%) of the participants suggested that adhering to code of ethics will help in reducing ethical and legal issues.

Significant factors affecting knowledge, attitude and practice of participants towards nursing ethics and law are presented on Table 6. Professional qualification $(p=.015)$, years of experience $(p=.000)$ and rank $(p=.002)$ had statistical significance on some variables of nursing ethics and law while age and sex did not.

Table 4. Factors associated with participants' knowledge, attitude and practice towards nursing ethics and law

\begin{tabular}{|c|c|c|c|}
\hline Variables & $\bar{n}$ & $\chi^{2}$ & $P$-value \\
\hline \multicolumn{4}{|l|}{ Years of experience } \\
\hline Have you heard of ethical dilemma before & 138 & 54.60 & .000 \\
\hline What do you understand by beneficence & 138 & 50.52 & .020 \\
\hline $\begin{array}{l}\text { Ethical dilemmas require an individual to } \\
\text { make a choice between two equal } \\
\text { unfavourable alternatives }\end{array}$ & 138 & 25.72 & .058 \\
\hline Patient's wishes must always be adhered to & 138 & 28.71 & .231 \\
\hline $\begin{array}{l}\text { Who has the highest law suits among } \\
\text { healthcare providers in Nigeria } \\
\text { Professional rank }\end{array}$ & 139 & 32.54 & .114 \\
\hline $\begin{array}{l}\text { Consents should be obtained only for } \\
\text { operations, not for nursing procedures }\end{array}$ & 139 & 31.67 & .002 \\
\hline $\begin{array}{l}\text { Who do you approach when faced with } \\
\text { ethical and legal problems }\end{array}$ & 139 & 50.83 & .050 \\
\hline Professional qualification & & & \\
\hline $\begin{array}{l}\text { What ways do you think ethical and legal } \\
\text { issued can be reduced } \\
\text { Sex }\end{array}$ & 139 & 90.80 & .015 \\
\hline What do you understand by beneficence & 127 & 1.330 & .856 \\
\hline $\begin{array}{l}\text { Does Nigeria constitution legalized } \\
\text { termination of pregnancy } \\
\text { Age group }\end{array}$ & 136 & 4.387 & .223 \\
\hline Have you heard of ethical dilemma before & 138 & 31.625 & .137 \\
\hline Patient's wishes must always be adhered to & 138 & 13.533 & .139 \\
\hline
\end{tabular}

$p=0.05$ significance

\section{Discussion}

The findings of this study on knowledge, attitude and practice of nursing ethics and law among nurses at Federal Medical Centre Bida, revealed more female participants than their male counterparts with a giving female-male ratio of $5.1: 1$. Seventy percent of the participants were specialized registered nurses with Mean years of experience (12 \pm 8$)$ and most of them $(89 \%)$ were within the rank of Principal Nursing Officers or below. This is analytical that most of the participants were in their youthful and active years and could benefit from various nursing continuing education programs especially, on nursing ethics and law. These findings are in line with a study from Ibadan [5]where most of the participants were between the ages of 30 and 50 years, 71\% were specialized registered nurseswith years of experience between 11-30 years. Remarkably, three factors of professional progression in this study, professional qualification $(p=.015)$, years of experience $(p=.000)$ and rank 
$(p=.002)$ had noticeable effects on knowledge, attitude and practice of nursing ethics and law among the participants. Equally, years of experience had statistical significance on participants ethical knowledge of beneficence $(p=.020)$ while there is no statistical significant in years of experience with non-maleficence $(p=.542)$. This implied that, the more nurses attend to patients in their practice areas, the better aware they becomeabout ethical dilemma.

Majority $(83 \%)$ of the participants had previous knowledge about ethical dilemma mostly (36\%) through seminars/workshops followed by those (31\%) who knew about it right from their respective schools of training. The vast majority $(95 \%)$ of the participants knew the correct definition of ethical dilemma. In a related development $(37 \%)$ of the participants reported that they do faceethical problems on daily basis at work. This may be attributed to workshops, seminars and mandatory continuing professional and educational development programs (MCPDP) organized for all cadres of nurses and midwives by Nursing and Midwifery Council of Nigeria to maintain standards of knowledge and competencies in nursing and midwifery education and practice in Nigeria [14]. Likewise, this will go a long way to improve the efficiency of nurses in their various practice areas. These findingsagree with a study in Pinelands [15] where years of experience and professional qualification of nurses were important factors influencing their knowledge of legal and ethical aspects of nursing practice. Conversely, it is contrary to the declaration that $78 \%$ of Nigerian nurses have knowledge deficit on legal aspects of nursing practice [5].

A good percentage of the participants $(66 \%)$ preferred to approach their unit in-charge and distantly followed by those (17.10 percent) who indicated that they will approach the Head of the department for ethical and legal problems encountered at work. This agrees with Amsale's[4] assertion that lack of correct approach in addressing different contextual issues in nursing practice may lead the nurse to ethical dilemma. Equally, this is balanced with the commonly preferred opinion to settle matters at the unit/departmental level rather than taking it farther into higher levels.The findings fromthis study established that $99 \%$ of the participants knew that code of nursing ethics sets out the ethical behaviours expected of the all registered nurses. The entire $(100 \%)$ participants pointed out that documentation of nursing activities can be tendered in the law suits as evidence. This is in line with study [7, 8] statements, that documentation of nursing activities is very important as it is the legal tender for any nursing interaction and care. Conversely, Adekilekun[10] states thatproper documentation is another common source of litigation in Nigeria.

Another finding from this study revealed different opinions pertaining to practical ethics questions which suggested that $51 \%$ of the participants depicts that patients' wish must always be adhered to while $38 \%$ disagrees with this opinion. Conversely, $74 \%$ of the participants disagreed with the view that if patient wishes to die; he or she should be assisted in doing so. This findings disagree with [4] statement on euthanasia that, the nurse shall never assist; collaborate in taking life as an act of mercy even at the direct request of the patient or patient's relatives. It is good to note that $84 \%$ of the participants in this study signified that Nigeria constitution does not legalized termination of pregnancy. This supportsa report [1] that, in many African countries, abortion is still illegal. However, abortion is permissible for a registered medical doctor when conducted for medical indications. Any attempt to procure abortion in Nigeria is a crime unless it is performed to save the woman's life. The opinion of the participants on whetherconsent should be obtained only for operations not for nursing procedures shows that the majority $(83 \%)$ of the participants selected false. This implies that consents should be equally obtained for all the nursing procedures.

Several ways were identified by the participants as remedies to reduce ethical and legal issues. These include workshop, adherence to code of ethics, utilization of hospital policy, personal reading of books and listening to media. This is in line with a study [4] which declares that, ethical issues are real life issues and that there is no one way of resolving such problem. Each situation will be different, depending on the people involved and the context. He further stated that nurses are often confronted by ethical problems that require them to make ethical decisions that are in the best interest of the client and as well, preserve the integrity of all concerned. Nwona et al [1] asserted that social changes such as right to healthcare, increasing cost of healthcare and conflicting institutional policies create ethical problems. Every individual is supposed to be entitled to healthcare but some times the cost of healthcare is beyond the reach of many. When such people present in healthcare institutions where the policy states people must pay before they can receive treatment, the nurse is faced with the dilemma of whether to observe the code of ethics of nursing which ascribed four primary responsibilities to her, one of which is to alleviate the suffering of the client or to observe the policy which states that no-pay-no-treatment. As a nurse, you have ethical obligations to your clients, the agency that employed you and to your coworker. Therefore you must weigh competing factors when making ethical decisions.

\subsection{Study Limitations}

Data collection of this study would have taken place earlier which might have accorded authors ample time to collect data if not for the delay in ethics approval.

\section{Conclusion}

Based on the findings of this study, inference can be drawn, that most of the participants have good knowledge on nursing ethics and law. Although, participants have different opinions as regards following patients' wish always as some were of the opinion thatit is unethical to oblige patient's wishes at all times. The overall results of the study suggested that there is need for nurses to understand the relationship and limitations between ethics, hospital policy and legal issues as they relate to nursing practice. 


\section{Recommendations}

Based on the findings of this study, the following recommendations are made to improve the knowledge, attitude and practice of Nursing Ethics and Law among nurses:

1 There should be a forum where all nurses come together at least once in a month to carry out mortality review of all patients within a specified period to identify and forestall possible legal and ethical issues.

2 The department of nursing services and the management of all hospitals should collaborate to sponsor nurses to seminars, workshops, and symposiums.

3 There is the need to make provision for current journals related to nursing practice to improve nurses' knowledge on nursing ethics and law.

4 The nurses should be fortified with modern equipment and enough manpower to enhance their productivity in their respective hospitals.

5 There should be good interpersonal relationship between nurses and their patients and between junior nurses and their seniors. This will strengthen the delivery of quality nursing care to patients and preclude good mentorship among nurses.

\section{Acknowledgement}

The intuitive contributions of Dr. J.O. Jacob of Department of Chemistry, Federal University of technology Minna, CNO SaniYahayaand CNO Solomon Lami of Department of Nursing Services, Ahmadu Bello University Teaching Hospital Zaria are gratefully acknowledged. The authors wish to also acknowledge Mr. OMOdofin of Department of Nursing services, Federal Teaching Hospital Ido-Ekiti, and Mr. ABAfolabi of the Department of Nursing Services, ObafemiAwolowo University Teaching Hospitals Complex Ile-Ife for their useful comments on the final manuscript.

\section{References}

[1] E. I. Nwona, O.C Nwana, K. S. Olubiyi, NSS320: Nursing Ethics and Jurisprudence, Lagos. National Open University of Nigeria press; pp i-ii, 18-19, 22, 34, 69-70,111-116, 120
[2] J. A. Adewoyin. The Nurse and the Rule of law Abeokuta, Davis Igwe Consulting, 2004

[3] C. Chaloner. An introduction to ethics in nursing, nursing standard. 2007;21(32):42-46

[4] A. Cherie, A. H. Mekonen, T. Shimelse, Introduction to Professional Nursing and Ethics, Addis Ababa University press Ethiopia, 2006; pp i,67-72,81-82,106-108,110-111,123.

[5] M. O. Oyetunde, B. A. Ofi. Nurses knowledge of legal aspects of nursing practice in Ibadan Nigeria. Journal of Nursing Education and Practice.2013;3(9): 75-82203-8.

[6] S. Searle. Professional practice. A Southern African Nursing Perspective $4^{\text {th }}$ Ed. 2000 Pinetown: Butterworth.

[7] K. M. Lowrey. Legal and ethical issues in cancer genetics nursing.SeminOncolNurs. 2004;20(3):203-8.

[8] M. L. Matzo, D. W. Sherman,P. Nelson-Marten, A. Rhome, M. Grant. Ethical and legal issues in end-of-life care: content of the End-of-Life Nursing Education Consortium curriculum and teaching strategies.J Nurses Staff Dev. 2004 Mar-Apr; 20(2): 59-66. $\quad$ PMid:15071336 http://dx.doi.org/10.1097/00124645-200403000-00001

[9] Y. Teytelman. Effective nursing documentation and communication.SeminOncolNurs. 2002;18(2):121-7. PMID:12051163 http://dx.doi.org/10.1053/sonu.2002.32509.

[10] M.T. Adekilekun, Medical ethics in the face of emerging medico-legal issues in Nigeria. Department of Business Law, Faculty of Law, University of Ilorin, Ilorin, Nigeria. 2010; pp 5,8 .

[11] I. I. Akpabio. Ethical issue and nursing strategies for achieving professional standards in nursing education. Continental J. Nursing Science. 2011;3(1):7-15.

[12] I. T. Adeleke, A. O. Adekanye, S. A. Adefemi, et al, Knowledge, attitude and practice of confidentiality of patients' health records among healthcare professionals at Federal Medical Centre, Bida. Niger J Med. 2011;20(2):228-235.

[13] Nursing and Midwifery Council of Nigeria. Newsletter 4th Ed. 2001 Vol 2 Oct.

[14] A. J. Dorse, E.L. Stellenberg. Legal and ethical aspects of nursing practice in selected private hospitals in the Western Cape metropolitan area Stellenbosch University, Stellenbosch University press, 2008; pp iv,50-51. 